\title{
Study on the efficacy of ceftriaxone versus azithromycin for the treatment of uncomplicated enteric fever among the patients admitted in a tertiary level hospital
}

\author{
Sougata Mitra ${ }^{1 *}$, Masuma Khanam², M. Iqbal Hossain ${ }^{3}$, Rukhsana Quadir ${ }^{4}$
}

\author{
${ }^{1}$ Department of Pharmacology and Therapeutics, Pabna Medical College, Pabna, Bangladesh, \\ ${ }^{2}$ Department of Pharmacology and Therapeutics, Mugda Medical College, Dhaka, Bangladesh \\ ${ }^{3}$ Department of Pharmacology and Therapeutics, Rajshahi Medical College, Rajshahi, Bangladesh, \\ ${ }^{4}$ Department of Pharmacology and Therapeutics, Colonel Malek Medical College, Manikganj, Bangladesh
}

Received: 18 October 2021

Accepted: 08 November 2021

*Correspondence:

Dr. Sougata Mitra,

Email: mitrasougata31@gmail.com

Copyright: (C) the author(s), publisher and licensee Medip Academy. This is an open-access article distributed under the terms of the Creative Commons Attribution Non-Commercial License, which permits unrestricted non-commercial use, distribution, and reproduction in any medium, provided the original work is properly cited.

\begin{abstract}
Background: Typhoid fever is a severe debilitating and potentially life threating illness. In Bangladesh, typhoid fever is a round the year problem which sometimes take epidemic proportions. The reasons behind such occurrences are unsafe water supply, defective sewage system and unhygienic food handling practice. This study aimed to compare the efficacy of ceftriaxone and azithromycin in the treatment of uncomplicated enteric fever.

Methods: An observational study was conducted at the department of pharmacology in Dhaka medical college, Dhaka, Bangladesh. Data were collected from blood culture positive patients for Salmonella typhi and Salmonella paratyphi, who admitted in the Dhaka medical college and hospital, Dhaka during the period of July 2015 to June 2016. Data was collected by using a structured questioner, face to face interview, physical examination and investigation reports. Patients were hospitalized during the entire treatment period and at admission evaluation was made by history and physical examination in a structured format. Subjects ware asked regarding changes in symptoms and possible adverse effects of the study drugs. All patients were asked to return two weeks after completion of treatment for follow up. Blood culture of Salmonella typhi or Salmonella paratyphi were done in all cases. Total 91 patients were culture positive for either $S$. typhi or $S$. paratyphi which were finally studied.

Results: During the study period out of 91 patients, 51 were receiving ceftriaxone and 40 were receiving azithromycin. Clinical cure was achieved in 46 patients (90\%) of ceftriaxone group and in 31 patients (78\%) in the azithromycin group. There were no significant differences of clinical cure between both treatment groups $(p>0.05)$. Mean fever clearance time in ceftriaxone group was $3 \pm 1.4$ days and was $4 \pm 1.6$ days for azithromycin group. Difference in fever clearance time was statistically significant $(\mathrm{p}<0.05)$. No clinical relapses were detected in any study subject. No major side effects of both drugs occurred in any subject.

Conclusions: These results indicated that both ceftriaxone and azithromycin were effective against enteric fever caused by sensitive organisms and multi drug resistant $S$. typhi and $S$. paratyphi. It is concluded that ceftriaxone is more effective and can be a convenient alternative for the treatment of enteric fever, especially in developing countries like us where medical resources are scarce.
\end{abstract}

Keywords: Typhoid fever, Paratyphoid fever, Ceftriaxone, Azithromycin 


\section{INTRODUCTION}

Enteric fever-a more inclusive term for typhoid fever and paratyphoid fever-is a systemic infection caused by Salmonella enterica, including $S$. enterica serotype Typhi (S. typhi) and serotype Paratyphi (S. paratyphi). ${ }^{1}$ Typhoid is a continuous fever lasting 3 to 4 weeks. ${ }^{2}$ High fever, toxemia, constipation during the first week, complicated by encephalopathy and perforation during the third week of fever are the typical manifestations of the disease. ${ }^{3}$ In a classical case, the fever rises daily in a step ladder pattern during the first week, remains continuously high during the second and third weeks and comes down gradually by the fourth week. ${ }^{2}$ After a person ingests $S$. enterica serotype typhi, an asymptomatic period follows that usually lasts 7 to 14 days (range, 3 to 60$).{ }^{4}$ In Bangladesh, typhoid fever is a round the year problem which sometimes take epidemic proportions. From the public health point of view the reason behind such occurrences are unsafe water supply, defective sewage system and unhygienic food handling practice. High prevalence of typhoid fever was observed among the patients habituated with supply water without boiling and accustomed to junk food compared to solely homemade food. ${ }^{5}$ At least 21.7 million new cases emerge each year of which $90 \%$ occur in South East Asia, resulting in about 216000 deaths. ${ }^{6-8}$ Enteric fever is more common in urban than rural areas and among young children and adolescents. ${ }^{8}$ Blood cultures are the standard diagnostic method. ${ }^{4}$ A positive blood culture is diagnostic; blood cultures are positive in approximately $90 \%$ cases in the first week of fever, $75 \%$ cases in the second week, $60 \%$ cases in the third week and $25 \%$ thereafter till the subsidence of pyrexia. $^{9}$ The organisms may be recovered from the bloodstream at any stage of the illness, but are most commonly found during the first 7-10 days and during relapses. ${ }^{10}$ Emergence of drug resistance is a major challenge in the treatment of typhoid fever. ${ }^{6}$ During the late 1990s and early 2000s, several clones of multidrug resistant Salmonella emerged, and since then they have expanded worldwide. For instance, in Salmonella enterica serotype typhimurium, the genomic element that carries resistance to 5 antimicrobials (ampicillin, chloramphenicol, streptomycin, sulfonamides and tetracycline) may spread horizontally among other serotypes and acquire additional resistance determinants. ${ }^{11}$ The first case of chloramphenicol resistance was reported in 1982. MDR cases began to appear around 1990. Ciprofloxacin and ofloxacin resistance were first reported in Bangladesh in $8 \%$ of enteric fever cases in the year 2000. However, WHO recommends ciprofloxacin and ofloxacin for MDR cases and azithromycin, $3^{\text {rd }}$ generation cephalosporin and high dose older generation fluoroquinolones in nalidixic acid resistant cases. ${ }^{6}$ Definitive treatment of typhoid fever (enteric fever) is based on susceptibility. Until susceptibilities are determined, antibiotics should be empiric, for which there are various recommendations. ${ }^{12}$ Resistance to azithromycin and ceftriaxone is rarely reported and this is why they can be used as empirical therapy in enteric fever. ${ }^{6}$ Azithromycin, a member of the macrolide class of antibiotics, possesses many characteristics for effective and convenient treatment of enteric fever including in vitro activity against many enteric pathogens, excellent penetration into most of the tissues, and achievement of concentrations in macrophages and neutrophils that are 100-fold higher than concentrations in serum. ${ }^{13}$ Ceftriaxone has good broad-spectrum activity against gram-positive and gram-negative bacteria, including $S$. typhi. ${ }^{14}$ It has a long elimination half-life ranging from 6.4 to 8.8 hours, making it suitable for a once daily dose regimen. ${ }^{15,16}$ Both ceftriaxone and azithromycin are approved by FDA (U.S. food and drug administration), easily available, can be given to all age group including pregnant women, they reduce the duration of therapy, thereby reducing bed occupancy and hospital cost. For these reasons, it will be useful for the people of Bangladesh. This study is designed with a view to compare the efficacy of ceftriaxone and azithromycin for the treatment of uncomplicated enteric fever.

\section{Objectives}

General objective was to compare the efficacy of ceftriaxone and azithromycin for the treatment of uncomplicated enteric fever.

\section{METHODS}

This study was an observational study conducted at the department of pharmacology in Dhaka medical college, Dhaka, Bangladesh. The total duration of the study was 1 year from July 2015 to June 2016. Data were collected from blood culture positive patients for Salmonella typhi and Salmonella paratyphi, age $\geq 12$ years who admitted in the Dhaka medical college and hospital, Dhaka during this period. Blood culture of $S$. typhi or $S$. paratyphi were done in all cases. Total 91 patients were culture positive for either $S$. typhi or S. paratyphi which were finally studied.

Data was collected by using a structured questioner, face to face interview, physical examination and investigation reports. Patients were hospitalized during the entire treatment period and at admission evaluation was made by history and physical examination in a structured format. Oral temperature and physical examination findings are recorded daily. Subjects ware asked regarding changes in symptoms and possible adverse effects of the study drugs. Patients were discharged from the hospital after they became afebrile for at least two days. All patients were asked to return two weeks after completion of treatment for follow up.

The collected data was classified according to age, sex, place of living, occupation, monthly income, marital status, characteristics of fever, fever associated complaints, physical examination findings, laboratory findings, clinical response etc. The numerical data obtained from study were analyzed and significance of difference was estimated by using the statistical methods. Data were expressed in frequency, percentage, mean and 
standard deviation as applicable. Variable with a $\mathrm{p}<0.05$ were counted as significant and $p>0.05$ were counted as insignificant. All statistics were calculated with SPSS and MS excel software.

\section{Inclusion criteria}

Patients of both male and female $\geq 12$ years of age, patients with blood culture positive for Salmonella typhi or Salmonella paratyphi were included in the study.

\section{Exclusion criteria}

Patient aged below 12 years, pregnant and lactating mother, patient taking any antimicrobial agent before doing culture sensitivity test, associated complication of enteric fever like severe gastrointestinal bleeding, GIT perforation, visible jaundice, pneumonia, renal failure, shock etc., were excluded from the study.

\section{RESULTS}

A total of 91 patients had blood culture positive for S. typhi or $S$. paratyphi finally comprises the basis for analysis.

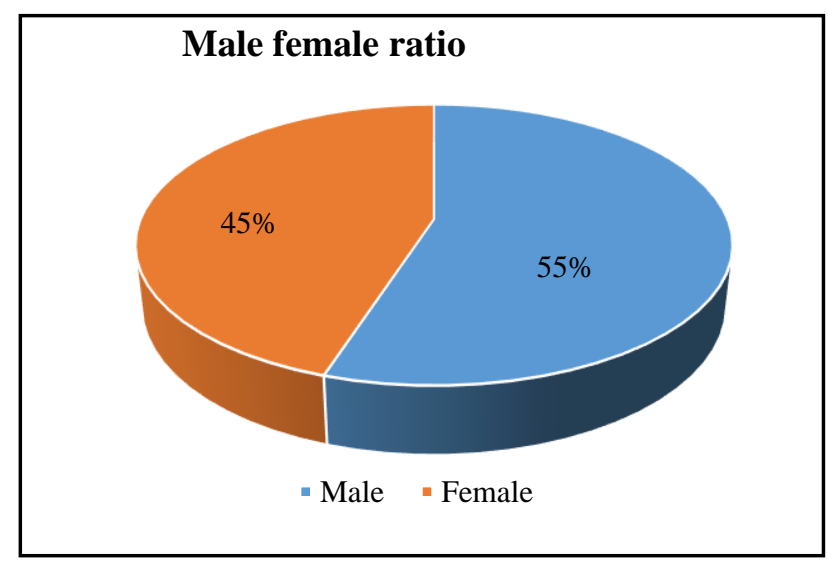

Figure 1: Sex distribution of sample population.

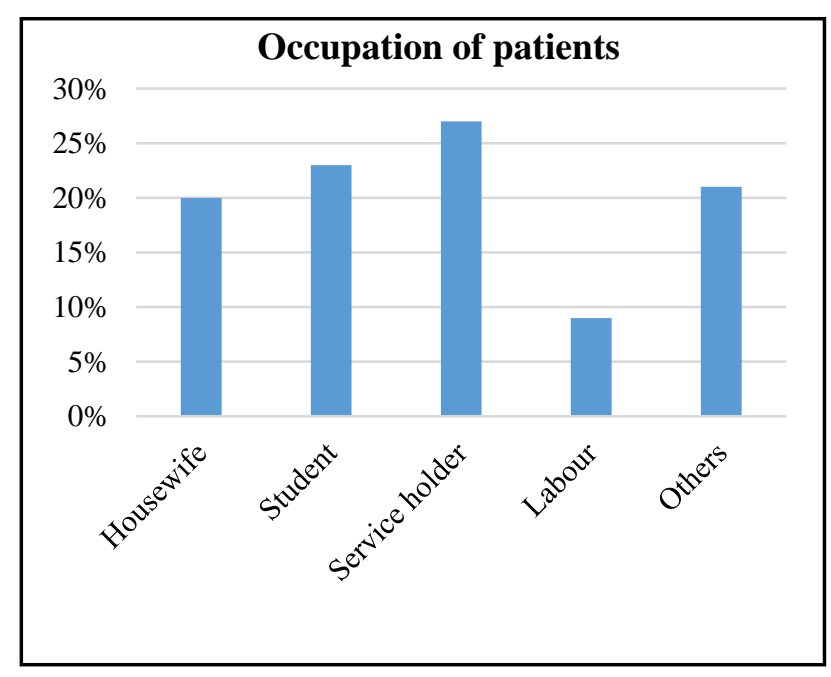

Figure 2: Occupation of sample population.
Table 1 and 2 shows the demographic and socioeconomic status of patients with culture positive enteric fever. Both male and females age ranging from 16 to 47 were affected with enteric fever. Male $(55 \%)$ are more affected than female $(45 \%)$ and male to female ratio was 1.2 : 1 . Most frequent age incidence in this study was 18 years. The high occurrence rate of typhoid fever observed among the service holders $(27 \%)$ and students $(23 \%)$. Most of the patients were from middle class $(54 \%)$ and poor $(32 \%)$ socioeconomic status and lived in slum like building $(55 \%)$ or tin-shade $(45 \%)$ house. Table 3 shows duration of fever, nature of fever and family history of fever at the time of presentation in both ceftriaxone and azithromycin groups. The majority of the patients attended between $1^{\text {st }}$ to $2^{\text {nd }}$ weeks of their illness; few in the $3^{\text {rd }}$ week. Classic continued type of fever was present in only $60 \%$ of patients in both treatment groups. The rise of temperature in stepladder pattern was found in only 53 cases among 91 patients (58\%). Table 4 shows number and percentage of symptoms of enteric fever. Fever was present in all cases i.e., $100 \%$. The most common symptoms other than fever were nausea and vomiting in both groups in 69 patients (76\%). Next common symptoms were headache (58\%), abdominal discomfort $(56 \%)$, chill $(49 \%)$, cough $(23 \%)$, constipation $(22 \%)$, diarrhoea $(16 \%)$ which was present in both treatment groups. Majority of the patients had temperature in the range of $102 \pm 1^{\circ} \mathrm{F}$ in both treatment groups. Relative bradycardia was present in $45 \%$ in ceftriaxone group and $65 \%$ in azithromycin group. Tongue was coated centrally with clear margin in $49 \%$ in ceftriaxone group and in $52 \%$ in azithromycin group. Splenomegaly was present in $51 \%$ in ceftriaxone group and $48 \%$ in azithromycin group. Hepatomegaly was present in $71 \%$ patients in ceftriaxone group and in $77 \%$ in azithromycin group. Jaundice, abdominal distension, rose spots and palpable lymph nodes were not found in any cases. In Table 6 there are laboratory investigational findings of both treatment groups. Hemoglobin level was $11.82 \pm 1.80 \mathrm{gm} / \mathrm{dl}$ in ceftriaxone group and was $11.99 \pm 1.75 \mathrm{gm} / \mathrm{dl}$ in azithromycin group. Total count of WBC was $6334 \pm 1434 /$ cu.mm in ceftriaxone group and was $6568 \pm 1440 /$ cu.mm in azithromycin group. In both treatment group serum bilirubin $(0.809 \pm 0.08$ and $0.821 \pm 0.077 \mathrm{mg} / \mathrm{dl})$, AST $(43.43 \pm 14.87$ and $42.25 \pm 13.08$ IU) and serum creatinine $(1.03 \pm 0.26$ and $1.05 \pm 0.285$ $\mathrm{mg} / \mathrm{dl})$ levels were within normal range. Table 7 shows serological test (Widal test) and blood culture reports of all culture positive patients in both treatment groups. Widal test shows initial positive result of rising titre of $\mathrm{TO} \geq 1: 320$ in $84 \%$ cases in ceftriaxone group and $78 \%$ in azithromycin group. Blood culture revealed growth of $S$. typhi in 83 patients $(91 \%)$ and $S$. paratyphi in 8 patients $(9 \%)$. In ceftriaxone group, 46 patients $(90 \%)$ revealed growth of $S$. typhi and 5 patients (10\%) revealed growth of $S$. paratyphi. In azithromycin group, blood culture revealed growth of $S$. typhi in 37 patients (92\%) and $S$. paratyphi in 3 patients (8\%). Clinical responses were cures or improvements within 5 days of starting treatment in $90 \%$ of patients treated with ceftriaxone and $78 \%$ of patients treated with azithromycin. In both treatment groups, responses to treatment were significant, that means 
both the drugs were effective in treating enteric fever. Difference in response to both groups was statistically insignificant $(p>0.05)$. Difference in fever clearance time was statistically significant $(\mathrm{p}<0.05)$. Those patients of ceftriaxone group who failed to response at day 5 after starting treatment, same treatment (Inj. ceftriaxone 80 $\mathrm{mg} / \mathrm{kg} /$ day intravenously in a single or two divided daily doses) was continued. Three patients had clinical improvement on day 7. For other 2 patients, inj. ceftriaxone $(80 \mathrm{mg} / \mathrm{kg} /$ day $)$ was given for the next $10-14$ days. No patient in ceftriaxone group developed complication. Among the azithromycin group 9 patients had no response at day 5 after starting treatment. For no responder patients, same treatment (Azithromycin 20 $\mathrm{mg} / \mathrm{kg} /$ day orally or IV once daily) for another 2 days was given. Subsequently 6 patients became afebrile on day 7 . For other 3 patients in azithromycin group, the treatment was switched over to inj. ceftriaxone $(80 \mathrm{mg} / \mathrm{kg} / \mathrm{day})$ for 10-14 days. Patients in both ceftriaxone and azithromycin treatment groups, who responded to therapy, the mean time to defervescence was more or less same. It was $3 \pm 1.4$ days for ceftriaxone group and was $4 \pm 1.6$ days for azithromycin group. Though percentage of response to treatment was $90 \%$ for ceftriaxone group and $78 \%$ for azithromycin group was different, but there was no statistically significant difference in both treatment groups ( $>0.05)$. There was statistically significant difference $(\mathrm{p}<0.05)$ in fever clearance time in both treatment groups. A total 63 of 91 (69\%) patients returned for follow up at 2 weeks. Twenty-eight patients were communicated over telephone. No patients develop clinical relapse on follow up.

Table 1: Demographic and socioeconomic status of patients with culture positive enteric fever before treatment.

\begin{tabular}{|lll|}
\hline $\begin{array}{l}\text { Parameters } \\
\text { Age (years) }\end{array}$ & $\begin{array}{l}\text { Patients } \\
\text { number }\end{array}$ & Percentage (\%) \\
\hline Mean \pm SD & $23.30 \pm 7.89$ & - \\
\hline Range & $16-47$ & \\
\hline Sex & & \\
\hline Male & 50 & 55 \\
\hline Female & 41 & 45 \\
\hline M:F (Ratio) & $1.2: 1$ & - \\
\hline Occupation & & \\
\hline Housewife & 18 & 20 \\
\hline Student & 21 & 23 \\
\hline Service holder & 25 & 27 \\
\hline Labour & 8 & 9 \\
\hline Others & 19 & 21 \\
\hline Socioeconomic status & \\
\hline Rich & 13 & 14 \\
\hline Middle class & 49 & 54 \\
\hline Poor & 29 & 32 \\
\hline Housing & & \\
\hline Building & 50 & 55 \\
\hline Tin-shade & 41 & 45 \\
\hline
\end{tabular}

Table 2: Comparison of demographic and socioeconomic status of ceftriaxone $(n=51)$ and azithromycin groups $(n=40)$.

\begin{tabular}{|lllll|}
\hline & \multicolumn{2}{l}{ Ceftriaxone } & \multicolumn{2}{l|}{ Azithromycin } \\
\hline Variables & N & \% & N & \% \\
\hline Age (Years) & & & & \\
Mean \pm SD & $23.37 \pm$ & & $23.22 \pm$ & - \\
& 8.04 & & 7.80 & \\
\hline Range & $16-47$ & - & $16-47$ & - \\
\hline Sex & & & & \\
\hline Male & 31 & 61 & 19 & 48 \\
\hline Female & 20 & 39 & 21 & 52 \\
\hline M:F (Ratio) & $1.5: 1$ & & $1: 1.1$ & \\
\hline Occupation & & & & \\
\hline Housewife & 9 & 18 & 9 & 23 \\
\hline Student & 14 & 27 & 7 & 18 \\
\hline Service holder & 14 & 27 & 11 & 27 \\
\hline Labour & 6 & 12 & 2 & 5 \\
\hline Others & 8 & 16 & 11 & 27 \\
\hline Socioeconomic status & & & \\
\hline Rich & 6 & 12 & 7 & 17 \\
\hline Middle class & 29 & 57 & 20 & 50 \\
\hline Poor & 16 & 31 & 13 & 33 \\
\hline Housing & & & & \\
\hline Building & 27 & 53 & 23 & 57 \\
\hline Tin-shade & 24 & 47 & 17 & 43 \\
\hline
\end{tabular}

Table 3: Comparison of initial fever characteristics between ceftriaxone $(n=51)$ and azithromycin groups $(n=40)$.

\begin{tabular}{|lccll|}
\hline & \multicolumn{2}{c}{ Ceftriaxone } & \multicolumn{3}{c|}{ Azithromycin } \\
\hline Variables & $\mathbf{N}$ & $\boldsymbol{\%}$ & $\mathbf{N}$ & \% \\
\hline $\begin{array}{l}\text { Initial fever } \\
\text { duration (Day) }\end{array}$ & $8.43 \pm 3.26$ & - & $8.17 \pm 3.41$ & - \\
\hline Nature of fever & (Frequency) & & & \\
\hline Continued & 31 & 34 & 24 & 26 \\
\hline Intermittent & 20 & 22 & 16 & 18 \\
\hline Family history of fever & & & \\
\hline Yes & 21 & & 20 & \\
\hline No & 30 & & 20 \\
\hline
\end{tabular}

Table 4: Initial fever associated complaints of enteric fever patients $(n=91)$.

\begin{tabular}{|lll|}
\hline Parameters & N & $\%$ \\
\hline Chill & 45 & 49 \\
\hline Rigor & 16 & 18 \\
\hline Headache & 53 & 58 \\
\hline Malaise & 8 & 9 \\
\hline Nausea and vomiting & 69 & 76 \\
\hline Cough & 21 & 23 \\
\hline Myalgia & 6 & 7 \\
\hline Arthralgia & 5 & 5 \\
\hline Constipation & 20 & 22 \\
\hline Diarrhoea & 15 & 16 \\
\hline Abdominal discomfort & 51 & 56 \\
\hline
\end{tabular}


Table 5: Comparison of initial examination findings of ceftriaxone $(n=51)$ and azithromycin groups $(n=40)$ of enteric fever patients.

\begin{tabular}{|c|c|c|c|c|}
\hline \multirow[t]{2}{*}{ Variables } & \multicolumn{2}{|c|}{$\begin{array}{l}\text { Ceftriaxone } \\
\text { groups }\end{array}$} & \multicolumn{2}{|c|}{$\begin{array}{l}\text { Azithromycin } \\
\text { groups }\end{array}$} \\
\hline & $\mathbf{N}$ & $\%$ & $\mathbf{N}$ & $\%$ \\
\hline $\begin{array}{l}\text { Temperature } \\
\left({ }^{\circ} \text { F) (Mean } \pm\right. \\
\text { SD) }\end{array}$ & $102 \pm 1$ & & $102 \pm 1$ & \\
\hline $\begin{array}{l}\text { Pulse } \\
\text { (beats/min) } \\
(\text { Mean } \pm \text { SD) }\end{array}$ & $106 \pm 6$ & & $103 \pm 6$ & \\
\hline \multicolumn{5}{|c|}{ Relative bradycardia } \\
\hline Yes & 23 & 45 & 26 & 65 \\
\hline No & 28 & 55 & 14 & 35 \\
\hline $\begin{array}{l}\text { SBP }(\mathrm{mmHg}) \\
(\text { Mean } \pm \text { SD) }\end{array}$ & $110 \pm 12$ & & $113 \pm 13$ & \\
\hline $\begin{array}{l}\text { DBP }(\mathrm{mmHg}) \\
(\text { Mean } \pm \text { SD) }\end{array}$ & $70 \pm 8$ & & $72 \pm 7$ & \\
\hline \multicolumn{5}{|l|}{ Anemia } \\
\hline Yes & 7 & 14 & 5 & 13 \\
\hline No & 44 & 86 & 35 & 87 \\
\hline \multicolumn{5}{|l|}{ Jaundice } \\
\hline Yes & 0 & 0 & 0 & 0 \\
\hline No & 51 & 100 & 40 & 100 \\
\hline \multicolumn{5}{|c|}{ Tongue (Coated) } \\
\hline Yes & 25 & 49 & 21 & 52 \\
\hline No & 26 & 51 & 19 & 48 \\
\hline \multicolumn{5}{|c|}{ Abdominal tenderness } \\
\hline Yes & 9 & 18 & 8 & 20 \\
\hline No & 42 & 82 & 32 & 80 \\
\hline \multicolumn{5}{|l|}{ Hepatomegaly } \\
\hline Yes & 36 & 71 & 31 & 77 \\
\hline No & 15 & 29 & 9 & 23 \\
\hline \multicolumn{5}{|l|}{ Splenomegaly } \\
\hline Yes & 26 & 51 & 19 & 48 \\
\hline No & 25 & 49 & 21 & 52 \\
\hline
\end{tabular}

Table 6: Comparison of laboratory findings of ceftriaxone $(n=51)$ and the azithromycin $(n=40)$ groups.

\begin{tabular}{|lll|}
\hline Variables & $\begin{array}{l}\text { Ceftriaxone } \\
\text { group, } \\
\text { (Mean } \pm \text { SD) }\end{array}$ & $\begin{array}{l}\text { Azithromycin } \\
\text { group, } \\
\text { (Mean } \pm \text { SD) }\end{array}$ \\
\hline Hb (gm/dl) & $11.82 \pm 1.80$ & $11.99 \pm 1.75$ \\
\hline $\begin{array}{l}\text { Total count of } \\
\text { WBC } \\
\text { (cu. mm) }\end{array}$ & $6334 \pm 1434$ & $6568 \pm 1440$ \\
\hline $\begin{array}{l}\text { Serum } \\
\text { bilirubin } \\
\text { (mg/dl) }\end{array}$ & $0.809 \pm 0.08$ & $0.821 \pm 0.077$ \\
\hline AST (IU) & $43.43 \pm 14.87$ & $42.25 \pm 13.08$ \\
\hline $\begin{array}{l}\text { Serum } \\
\text { creatinine } \\
\text { (mg/dl) }\end{array}$ & $1.03 \pm 0.26$ & $1.05 \pm 0.285$ \\
\hline
\end{tabular}

*AST-Aspartate aminotransferase
Table 7: Comparison of serological and culture findings of ceftriaxone $(n=51)$ and azithromycin $(n=40)$ groups.

\begin{tabular}{|lllll|}
\hline Variables & $\begin{array}{l}\text { Ceftriaxone } \\
\text { group, } \\
\text { (Mean }\end{array}$ & +SD) & \multicolumn{2}{l|}{$\begin{array}{l}\text { Azithromycin } \\
\text { group, } \\
\text { (Mean }\end{array}$} \\
\hline Widal test & & \% & N & \% \\
\hline Positive & 43 & 84 & 31 & 78 \\
\hline Negative & 8 & 16 & 9 & 22 \\
\hline Blood culture & & & & \\
\hline S. typhi & 46 & 90 & 37 & 92 \\
\hline S. paratyphi & 5 & 10 & 3 & 8 \\
\hline
\end{tabular}

Table 8: Comparison of clinical response of ceftriaxone $(n=51)$ and azithromycin $(n=40)$ groups.

\begin{tabular}{|lllll|}
\hline Variables & $\begin{array}{l}\text { Ceftriaxone } \\
\text { group }\end{array}$ & \multicolumn{2}{c|}{$\begin{array}{l}\text { Avithromycin } \\
\text { group }\end{array}$} \\
\hline N & $\%$ & N & $\%$ \\
\hline $\begin{array}{l}\text { Clinical cure } \\
\text { on or before } \\
\text { day 5 }\end{array}$ & 46 & 90 & 31 & 78 \\
$\begin{array}{l}\text { No. of days to } \\
\text { defervescence } \\
\text { after start of } \\
\text { treatment } \\
\text { (mean } \pm \text { SD) }\end{array}$ & $3 \pm 1.4$ & - & $4 \pm 1.6$ & - \\
$\chi 2=2.76, p>0.05$ & & & & \\
\hline
\end{tabular}

\section{DISCUSSION}

The present study was concerned with the comparison of the efficacy of ceftriaxone and azithromycin in the treatment of uncomplicated enteric fever. In this study, 91 consecutive blood culture positive cases of enteric fever admitted into Dhaka medical college and hospital, Dhaka were selected for final analysis. However complete clinical response at discharge and no relapse on follow up was considered as cure. During the whole process of study, maximum efforts were exerted to get clinical information from the patients as much as possible. Data regarding age, sex, socioeconomic status, occupation, prior history of contact with enteric fever cases and the clinical presentation were noted. Children and young adult had the highest age-specific rates of enteric infection. ${ }^{17}$ In this study the age of the patients was between 16-47 $(\geq 12)$ years. Maximum numbers of patients were in the age group of 18 years. This may be due to young people are more exposed to Salmonella because they go outside more and eat outside food frequently. In this study, no case was recorded above 47 years. This study shows overall preponderance of male over female (1.2:1). Similar results were found in other studies by Mutanabbi et al and Rahman et al in Bangladesh. ${ }^{18,19}$ Most of the patients were from middle class $(54 \%)$ and poor $(32 \%)$ socioeconomic status and lived in slum like building $(55 \%)$ or tin-shade (45\%) house. This may be due to overcrowding, poor sanitation, gross ignorance of the value of pure drinking 
water, proper disposal of sewage. All the patients in this study came with fever and duration of fever varied from 3 days to 3 weeks. Maximum cases presented in the $2^{\text {nd }}$ week and rest are in the $1^{\text {st }}$ week. Majority of the patients had temperature in the range of $101-103^{\circ} \mathrm{F}$. Most frequent temperature recorded at the time of presentation was $102^{\circ} \mathrm{F}$. This is similar to the findings of another study by Banu et al in Bangladesh, where $68 \%$ of patients exhibited a temperature ranging from $101-102^{\circ} \mathrm{F}, 24 \%$ exhibited $103^{\circ} \mathrm{F}^{20}$ The most prominent symptom is prolonged fever $\left(38.8^{\circ}-40.5^{\circ} \mathrm{C} ; 101.8^{\circ}-104.9^{\circ} \mathrm{F}\right)$, which can continue for up to 4 weeks if untreated. ${ }^{21}$ In this study $60 \%$ patients showed continued type of fever and $40 \%$ showed intermittent type. This study shows $58 \%$ patients with stepladder rise of temperature and in rest of patient's temperature rise were sudden onset. It is similar to the study by Islam et al in Dhaka where they found stepladder rise of temperature in $57 \%$ and intermittent fever in $43 \%$ of cases. ${ }^{22}$ Signs of enteric fever in both treatment groups show relative bradycardia which was present in $45 \%$ and $65 \%$ of patients in ceftriaxone and azithromycin group respectively. This is similar to the study by Islam et al in Dhaka where they found relative bradycardia in $43.2 \%$ cases. $^{22}$ Coated tongue with clear margin was present in $49 \%$ and $52 \%$ patients of ceftriaxone and azithromycin group. This finding is similar to those of Jyoti et al study where coated tongue present in $49.5 \%$ of cases. ${ }^{23}$ In this study hepatomegaly was present in $71 \%$ and $77 \%$ patients and splenomegaly in $51 \%$ and $48 \%$ patients of ceftriaxone and azithromycin group respectively. Present findings are comparable to Islam et al study where hepatomegaly was present in $78.4 \%$ and splenomegaly in $60.2 \%$ cases. $^{22}$ Hemoglobin estimation is done in all cases and was (Mean \pm SD) $11.82 \pm 1.80 \mathrm{gm} / \mathrm{dl}$ in ceftriaxone group and $11.99 \pm 1.75 \mathrm{gm} / \mathrm{dl}$ in azithromycin group patients. Total count of WBC was $6334 \pm 1434$ /cu.mm in ceftriaxone group and was $6568 \pm 1440$ /cu.mm in azithromycin group. None of the patients had leukocytosis. In both treatment group serum bilirubin $(0.809 \pm 0.08$ and $0.821 \pm 0.077$ $\mathrm{mg} / \mathrm{dl})$, AST $(43.43 \pm 14.87$ and $42.25 \pm 13.08 \mathrm{IU})$ and serum creatinine $(1.03 \pm 0.26$ and $1.05 \pm 0.285 \mathrm{mg} / \mathrm{dl})$ levels were within normal range. Widal test was significant in $84 \%$ patients of ceftriaxone group and $78 \%$ patients of azithromycin group. In this study, 91 patients were culture positive for either $S$. typhi or $S$. paratyphi. Out of 91 patients, $83(91 \%)$ were culture positive for S. typhi and 8 ( $9 \%$ ) were culture positive for $S$. paratyphi. These findings are consistent with some earlier studies by Saha et al and Rahat et al. ${ }^{24,25}$ Only culture positive patients were evaluated. Out of 91 patients, 51 were receiving ceftriaxone and forty (40) were receiving azithromycin. In ceftriaxone group 46 patients $(90 \%)$ revealed growth of $S$. typhi and 5 patients $(10 \%)$ revealed growth of S. paratyphi. In azithromycin group blood culture revealed growth of $S$. typhi in 37 patients $(92 \%)$ and $S$. paratyphi in 3 patients (8\%). S. typhi infection is more prevalent than S. paratyphi infection. Stool and urine culture was not done in this study. Clinical cure was achieved in 46 patients $(90 \%)$ in ceftriaxone group and in 31 patients $(78 \%)$ in the azithromycin group. It took average $3 \pm 1.4$ days for remission of fever in ceftriaxone group and $4 \pm 1.6$ days in azithromycin group. Adverse effects like nausea, vomiting, anorexia, dry throat, dizziness, weakness etc. were reported occasionally in both treatment groups. A total 63 of $91(69 \%)$ patients returned for follow up at 2 weeks. Though all patients did not come for follow up, the patients who came had no clinical relapse on the $2^{\text {nd }}$ weeks post treatment follow up. Moreover 28 patients were contacted over telephone for follow up, but no patient complains of development of fever within that period.

\section{CONCLUSION}

In this study, ceftriaxone appears to be as effective as azithromycin in treating enteric fever. Firm conclusion is not possible to draw from this study with limited scope. We cannot claim this study as an exact reflection of whole population. Further study with repeated culture facilities to prove both microbiological as well as clinical cure will be very much helpful for establishing ceftriaxone in the treatment of enteric fever.

\section{Funding: No funding sources}

Conflict of interest: None declared

Ethical approval: The study was approved by the Institutional Ethics Committee

\section{REFERENCES}

1. Connor BA, Schwartz E. Typhoid and paratyphoid fever in travelers. Lancet Infect Dis. 2005;5:623-8.

2. Roy RN, Saha I. Mahajan and Gupta Textbook of Preventive and Social Medicine. $4^{\text {th }}$ edition. India: Jaypee Brothers Medical Publishers. 2013;230.

3. Dutta TK, Beeresha, Ghotekar LH. Atypical manifestations of typhoid fever. J Postgrad Med. 2001;47(4):248-51.

4. Parry CM, Hien TT, Dougan G, White NJ, Farrar JJ. Typhoid fever. N Engl J Med 2002;347(22):1770-82.

5. Rahman AKMM, Ahmad M, Begum RS, Hossain MZ, Hoque SA, Matin A et al. Prevalence of typhoid fever among the children in a semi urban area of Bangladesh. J Dhaka Med Coll. 2011;20(1):37-43.

6. Rahman AKMM, Ahmad M, Begum RS, Ghosh AK, Hossain MZ. Multidrug resistant typhoid fever in children: A review. J Dhaka Med Coll. 2008;17(2):121-6.

7. Ochiai RL, Acosta CJ, Danovaro-Holliday MC, Baiqing D, Bhattacharya SK, Agtini MD et al. A study of typhoid fever in five Asian countries: disease burden and implications for controls. Bull World Health Org. 2008;86:260-8.

8. Pegues D. Enteric fever. Infectious Disease Advisor 2017, 2013. Available at: https://www.infectious diseaseadvisor.com/home/decision-support-inmedicine/infectious-diseases/enteric-fever/

9. Kanungo R. Ananthanarayan and Paniker's Textbook of Microbiology. $10^{\text {th }}$ edition. India: The Orient Blackswan. 2017;302. 
10. Greenwood D, Barer M, Slack R, Irving W. Medical Microbiology. $18^{\text {th }}$ edition. UK: Churchill Livingstone Elsevier. 2012;270.

11. Antimicrobial Resistance: Global Report on Surveillance. World Health Organization 2014. P 24. Available at: https://apps.who.int/iris/bitstream/ handle/10665/112642/9789241564748_eng.pdf. Accessed on 25 April, 2021.

12. Brusch JL, Garvey T, Corales R, Schmitt SK, Talavera F, Brown RB et al. Typhoid fever. MedScape. 2019. Available at: https://emedicine.medscape.com/article/231135print. Accessed on 25 April, 2021.

13. Sreenivasa B, Manjunatha B, Joseph N. To compare the effectiveness of oral azithromycin versus intravenous ceftriaxone for treating uncomplicated enteric fever. Indian J Child Health. 2016;3(3):230-3.

14. Neu HC, Meropol NJ, Fu KP. Antibacterial Activity of Ceftriaxone (Ro 13-9904), a $\beta$-Lactamase-Stable Cephalosporin. Antimicro agents chemotherapy. 1981;19(3):414-23.

15. Patel IH, Chen S, Parsonnet M, Hackman MR, Brooks MA, Konikoff $\mathrm{J}$ et al. Pharmacokinetics of Ceftriaxone in Humans. Antimicro agents chemotherapy. 1981;20(5):634-41.

16. Schaad UB, Stoeckel K. Single-Dose Pharmacokinetics of Ceftriaxone in Infants and Young Children. Antimicro agents chemotherapy. 1982;21(2):248-53.

17. Chowdhury MAJ, Shumy F, Anam AM, Chowdhury MK. Current status of typhoid fever: a review. Bangladesh Med J. 2014;43(2):106-11.

18. Mutanabbi M, Islam KA, Helal MA, Mamun HA, Quader M, Ahmed S. Retrospective analysis of 52 cases of enteric fever in a tertiary care hospital in Dhaka city. Bangl J Med. 2010;21:71-3.
19. Rahman M, Ahmed ASM NU, Iqbal J, Mamun AA, Hossain N, Islam A. Socio-Demographic Factors Affecting the Prevalence of Enteric Fever: A Study in a Tertiary Care Hospital, Dhaka, Bangladesh. Scholars J Appl Med Sci. 2020;8(8):1927-31.

20. Banu A, Rahman MJ, Suza-ud-doula A, Majumder B, Mostakim MA, Rahman M et al. Clinical profile of typhoid fever in children in northern areas of Bangladesh. Dinajpur Med Col J. 2016;9(1):53-8.

21. Jameson JL, Fauci AS, Kasper DL, Hauser SL, Longo DL, Loscalzo J. Harrison's Principles of Internal Medicine. $20^{\text {th }}$ edition. USA: The McGraw-Hill Education. 2018;1175.

22. Islam S, Rahman H, Karim B, Khan RH. Clinical Presentation of Typhoid Fever. Ibrahim Card Med J. 2011;1(2):40-4.

23. Jyoti D, Gupta NP, Vijay C, Agarwal A, Kumari S. Clinical and laboratory profile of typhoid fever in children in North Bihar. Int $\mathrm{J}$ Health Clin Res. 2020;3(12S):218-23.

24. Saha SK, Saha S, Sayeed KMI, Saha S, Islam S, Rahaman A et al. Hospitalization of Pediatric Enteric Fever Cases, Dhaka, Bangladesh, 2017-2019: Incidence and Risk Factors. Clin Infectious Dise. 2020;71(S3):196-204.

25. Rahat F, Ghosh NK, Iman K, Khanam M, Sultana A, Haque F. Clinico-laboratory Profile of Enteric Fever and Antibiotic Sensitivity Pattern in Hospitalized Children. Bangl J Child Health. 2018;42(2):54-7.

Cite this article as: Mitra S, Khanam M, Hossain MI, Quadir R. Study on the efficacy of ceftriaxone versus azithromycin for the treatment of uncomplicated enteric fever among the patients admitted in a tertiary level hospital. Int J Basic Clin Pharmacol 2022;1:1-7. 